PROF. FABIENNE DOBBELS (Orcid ID : 0000-0002-9502-7374)

Article type : Original Article

\title{
HOW TO SCREEN FOR AT RISK ALCOHOL USE IN TRANSPLANT PATIENTS? FROM INSTRUMENT SELECTION TO IMPLEMENTATION OF THE AUDIT-C
}

Lieza Verhalle, RN, MSN ${ }^{1}$; Kristof Van Bockstaele, RN, MSN ${ }^{1}$; Nathalie Duerinckx, MSN, PhD 1,2; Jasper Vanhoof, MSN, PhD 1, 3; Katrien Dierickx, RN, MSN 3; Leen Neyens, MSc ${ }^{4}$; Johan Van Cleemput, MD, PhD 2 ; Sabine Gryp, RN, MSN 2; Dominica Kums, RN 2; Katleen De Bondt, RN, MSN 4; Veronique Schaevers, RN, MSN ${ }^{5}$; Florian Demuynck, RN, MSN ${ }^{1}$; Anne Dewispelaere, RN, MSN ${ }^{1}$; Fabienne Dobbels, MSc, PhD ${ }^{1}$, on behalf of the Transplantation Innovation Team (TRANSIT)

\section{Running title: alcohol screening instrument for routine care}

\section{Author information:}

${ }^{1}$ Academic Centre for Nursing and Midwifery, Department of Public Health and Primary Care, KU Leuven, Leuven, Belgium

${ }^{2}$ Heart Transplant Program, Department of Cardiovascular Diseases, University Hospitals Leuven, Leuven, Belgium

${ }^{3}$ University Psychiatric Center, UPC KU Leuven, Leuven, Belgium

${ }^{4}$ Department of Nephrology, University Hospitals Leuven, Leuven, Belgium

${ }^{5}$ Lung Transplant Program, University Hospitals Leuven, Leuven, Belgium

\section{Transplantation Innovation Team (TRANSIT):}

Carine Breunig, RN: Abdominal Transplant Program, University Hospitals Leuven, Leuven, Belgium

This article has been accepted for publication and undergone full peer review but has not been through the copyediting, typesetting, pagination and proofreading process, which may lead to differences between this version and the Version of Record. Please cite this article as doi: $10.1111 /$ ctr.14137

This article is protected by copyright. All rights reserved 
Sabina De Geest, RN, PhD: Academic Centre for Nursing and Midwifery, Department of Public Health and Primary Care, KU Leuven, Belgium and Institute of Nursing Science, Department of Public Health, University of Basel, Basel, Switzerland

Kathy Goris, RN, MSN: Stem Cell Transplant Program, University Hospitals of Leuven, Leuven, Belgium Leen Pierco, RN: $\quad$ Liver Transplant Program, University Hospitals Leuven, Leuven, Belgium

Eva Puttevils, RN, MSN: Abdominal Transplant Program, University Hospitals of Leuven, Leuven, Belgium Annemieke Schoonis: Lung Transplant Program, University Hospitals of Leuven, Leuven Belgium Katrien Vandersmissen:Cardiac Surgery, University Hospitals of Leuven, Leuvne, Belgium Jolien Verheyen: Kidney Transplant Program, University Hospitals of Leuven, Leuven, Belgium Tess Wynants L Lung Transplant Program, University Hospitals of Leuven, Leuven,, Belgium

\section{Corresponding author:}

Fabienne Dobbels, MS, PhD

Department of Public Health and Primary Care

Academic Centre for Nursing and Midwifery

KU Leuven

Kapucijnenvoer 35/4

3000 Leuven

Belgium

Tel: +32 1637.34 .02

Fax: +32 1633.69 .70

E-mail: fabienne.dobbels@kuleuven.be

\section{Acknowledgements:}

The authors would like to thank all patients for their contribution and hospital staff for their support in conducting the study.

Funding statements: This research received no specific grant from any funding agency in the public, commercial, or not-for-profit sectors.

Keywords: at risk drinking, alcohol use, screening, solid organ transplantation

Data availability statement: Original data are available upon request by sending an e-mail to Fabienne.dobbels@kuleuven.be 


\section{HOW TO SCREEN FOR AT RISK ALCOHOL USE IN TRANSPLANT PATIENTS? FROM INSTRUMENT SELECTION TO IMPLEMENTATION}

Lieza Verhalle, RN, MSN ${ }^{1}$; Kristof Van Bockstaele, RN, MSN 1; Nathalie Duerinckx, MSN, PhD 1,2; Jasper Vanhoof, MSN, PhD 1, 3; Katrien Dierickx, RN, MSN 3; Leen Neyens, MSc 4; Johan Van Cleemput, MD, PhD ${ }^{2}$; Sabine Gryp, RN, MSN 2; Dominica Kums, RN 2; Katleen De Bondt, RN, MSN 4; Veronique Schaevers, RN, MSN 5; Florian Demuynck, RN, MSN 1; Anne Dewispelaere, RN, MSN ${ }^{1}$; Fabienne Dobbels, MSc, PhD ${ }^{1}$, on behalf of the Transplantation Innovation Team (TRANSIT)

\section{ABSTRACT}

Background: Given that drinking > 2- 3 units of alcohol daily might already have adverse health effects, regular screening of at risk drinking is warranted. We aimed to select and pilot a short instrument to accurately screen for at risk drinking in transplant patients.

Methodology and results: Five consecutive steps were completed: A comprehensive literature review identified 24 possible self-report instruments (step 1). These instruments were scored on six yes/no criteria (i.e. length, concept measured, diagnostic accuracy, population, manual available, cost) (step 2). Four nurses piloted three instruments with the highest score, and were interviewed on their experiences with using the AUDIT-C, TWEAK and Five-Shot. The AUDIT-C was the easiest to use and score, and items were clear. Cognitive debriefings with 16 patients were conducted to verify clarity of instructions and items, and suggestions were incorporated into a modified version of the AUDIT-C (step 4). A convenience sample of 130 Dutch-speaking heart transplant patients completed the modified AUDIT-C during a scheduled visit (Step 5), revealing that $27.6 \%$ of patients showed at risk drinking.

Conclusion: The AUDIT-C might be a suitable instrument to identify at risk drinking in routine posttransplant follow-up. Further validation, however, is indicated.

This article is protected by copyright. All rights reserved 
Key words: At risk drinking, alcohol use, screening, solid organ transplantation.

Corresponding author: Fabienne Dobbels, MSc, PhD; Academic Centre for Nursing and Midwifery, KU Leuven; Kapucijnenvoer 35/4; 3000 Leuven; Belgium; Fabienne.dobbels@kuleuven.be 


\section{BACKGROUND}

Drinking alcohol is a common and socially accepted behavior in many parts of the world, and the amount of alcohol consumption per capita continues to further increase over time ${ }^{1}$. This is surprising, given alcohol's intoxicating and dependence-producing characteristics. More specifically, the World Health Organization estimated that $5.3 \%$ of all deaths in 2016 were due to alcohol use, making it the third leading cause of death globally ${ }^{1}$. Currently, more than 200 diseases are known to be related to alcohol use, including cardiovascular disease, liver cirrhosis, some forms of cancer, mental disorders, obesity as well as injuries ${ }^{1}$.

However, it is important to make a distinction between substance use disorder, hazardous drinking and drinking alcohol in amounts that does not cause health problems or diseases. The Diagnostic and Statistical Manual 5th edition (DSM-V) defines 'substance use disorder' as a wide variety of problems arising from substance use, of which a minimum of two of 11 criteria need to be present, with criteria for instance referring to hazardous use, tolerance and social/interpersonal problems related to use, among other characteristics ${ }^{2}$. In contrast to previous editions of the DSM, a distinction between alcohol dependence or abuse is no longer being made. Hazardous drinking, also called at risk drinking, is defined as "a pattern of alcohol consumption that increases the risk of harmful consequences for the user or others. Hazardous drinking patterns are of public health significance despite the absence of any current disorder in the individual user ${ }^{2} . "$

Unfortunately, however, there is no universal agreement on how much alcohol one can drink without endangering one's health, and the guidelines on responsible drinking vary widely between countries ${ }^{3}$. Some countries use daily or weekly limits for men and woman, while other countries don't differentiate by gender. In Australia, for instance, men and women are told they should drink no more than 20 grams each day. American women are allowed 42 grams per day, but no more than 98 grams per week. In contrast, men in the United States are told they can safely drink 56 grams per day and up to 196 grams per week. In the UK, men and women are advised to drink no more than 14 units a week, and to spread them over the week rather than binge drinking. In stark contrast, the upper weekly limit for men in Poland is substantially higher with 280 grams per week. Moreover, despite the World Health Organization defining a standard drink as one containing 10 grams of alcohol, most countries use their own definition. A standard drink in Austria for instance contains 20 grams of alcohol, in the United States 14 grams and in Iceland and the United Kingdom 8 grams ${ }^{3}$.

This article is protected by copyright. All rights reserved 
Different screening measures were considered to detect hazardous drinking/at risk drinking, including the use of biomarkers ${ }^{4}$. However, in the light of busy outpatient clinic visits, where other medical and psychosocial assessments need to be completed, the transplant teams within our hospitals were in need of a validated, inexpensive, user friendly and short screening instrument that can easily be implemented in routine clinical practice.

The purpose of the present study therefore was to identify a self-report instrument that is most suitable to screen for at risk drinking in adult transplant patients, to implement it, and to determine the prevalence of at risk drinking in a cross-sectional study in heart transplant patients.

This article is protected by copyright. All rights reserved 


\section{METHODS AND RESULTS}

In line with the conceptual framework outlined by the Food and Drug Administration ${ }^{5}$, a stepwise approach was used to select the most suitable self-report instrument to screen for alcohol use in adult transplant patients, consisting of a) a comprehensive literature search, b) selection of potentially relevant instruments, c) piloting of selected instruments by nurses and d) cognitive debriefings in transplant patients. Ethical approval for these steps was obtained on February 16, 2016. The selected instrument was subsequently used in a cross-sectional study to determine the prevalence of at risk drinking in heart transplant patients. We defined at risk drinking as drinking more than 3 alcohol units daily for men, and more than 2 units for women (i.e. more than 21 or 14 units weekly), based on the guidelines set forward by the Federal Public Service of Belgium ${ }^{6}$. This study was approved by the ethical committee of the University Hospitals of Leuven on March 15, 2016. The next paragraphs describe the methodology and results for each step.

\section{STEP 1: LITERATURE SEARCH}

\section{METHODS}

\section{Design}

This step aimed to generate a comprehensive overview of self-report instruments currently being used to screen for at risk drinking in chronic patient populations, following the Cochrane guidelines on conducting a systematic review ${ }^{7}$. The reporting was done in concordance with the principles of the PRISMAguidelines ${ }^{8}$.

\section{Search approach, databases, search string, and inclusion and exclusion criteria}

The databases PubMed and the Cochrane Library were searched from inception until December 9, 2015, using a search string consisting of a combination of controlled Thesaurus terms and free text words referring to alcohol use and self-report instruments, respectively. Title and abstract screening was done by two researchers independently, followed by a full text analysis of potentially relevant publications, using the following inclusion criteria: the paper a) had to be written in English or Dutch, b) described the development and validation of a self-report screening instrument for alcohol use in adults or used a selfreport instrument investigating at risk drinking/alcohol abuse in adults in a quantitative study. Studies on pregnant women or people with psychiatric conditions were excluded, as well as comments or editorials. In addition, reviews on alcohol use were scrutinized for potentially additionally relevant self-report screening instruments.

This article is protected by copyright. All rights reserved 


\section{Data extraction}

The following data were extracted and tabulated by the same two researchers: instrument developer, purpose (i.e. at risk drinking, alcohol abuse, and excessive alcohol use), setting and population, number of questions, scoring, and information on reliability and validity (e.g. sensitivity, specificity, internal consistency).

\section{RESULTS}

In total, 24 unique screening instruments ${ }^{9-30}$ were found, of which their characteristics are summarized in table 1.

INSERT TABLE 1 ABOUT HERE

This article is protected by copyright. All rights reserved 


\section{STEP 2: SELECTION OF POTENTIALLY SUITABLE INSTRUMENTS TO SCREEN FOR AT RISK}

\section{DRINKING}

\section{METHODS}

The 24 instruments identified based on our literature review were subsequently evaluated against the following pre-specified criteria:

1) Is the screening instrument focusing on at risk drinking? (yes: 1, no: 0 )

2) Is the screening instrument sufficiently short (i.e. 5 items or less) in order to be useful in daily clinical practice? (yes: 1 , no: 0 )

3) Is there a manual available? (yes: 1 , no: 0 )

4) Does the sensitivity and specificity against a diagnostic interview as the gold standard has a higher average score than $\geq 0.70$ ? (yes: 1 , no: 0 ) (If not available, positive and negative predictive values were used with the same cut-off.)

5) Has the instrument been tested in a (non-psychiatric) hospital setting? (yes: 1, no: 0)

6) Can the instrument be used free of charge? (yes: 1 , no: 0 )

Scores per instrument are summed, yielding a score between 0 and 6 for each instrument, with higher scores indicating higher suitability for clinical practice.

Next, screening instruments with a score of 5 or 6 on these six criteria were discussed during a focus group with eight professionals with various backgrounds (i.e. nurses, psychologists, physicians), in order to select those self-report instruments with the highest face validity for use in clinical practice.

This article is protected by copyright. All rights reserved 


\section{RESULTS}

The scores per instrument are summarized in table 1. Only three instruments received a score of 6/6, i.e. the AUDIT-C ${ }^{10-12}$, TWEAK ${ }^{30}$ and Five-Shot ${ }^{25}$. Four instruments received a score of 5, i.e. the AUDIT 10-12, CAGE ${ }^{29}$, FAST ${ }^{24-25}$, T-ACE ${ }^{29}$. The AUDIT-C was preferred over the AUDIT ${ }^{10-12}$, as this is a shorter instrument with excellent sensitivity and specificity when tested against diagnostic interviews. The CAGE 29 focuses more on abuse or dependence, while we are more interested in instruments screening for at risk drinking. The Five Shot ${ }^{25}$ combines questions from the AUDIT and CAGE, while being sufficiently short, making the Five Shot a better option to consider. The FAST ${ }^{24-25}$ has not been tested in a hospital setting and there is no manual available from the T-ACE ${ }^{29}$.

Hence, the team concluded that only the AUDIT-C ${ }^{10-12}$, TWEAK ${ }^{30}$ and Five Shot ${ }^{25}$ could be further evaluated in the next steps. The TWEAK was only available in English, but translated by a certified medical translator working for One Hour Translation (onehourtranslation.com) into Dutch using the forwardbackward methodology in line with the guidelines of the Professional Society for Health Economics and Outcomes Research (ISPOR) for translation of patient reported outcome measures ${ }^{31}$.

\section{STEP 3: PILOTING OF THE THREE SELECTED INSTRUMENTS BY NURSES}

\section{METHODS}

Four nurses working at the heart transplantation ward or outpatient clinic of the University Hospitals of Leuven (Belgium) volunteered to use the three selected screening instruments (AUDIT-C ${ }^{10-12}$, Five Shot ${ }^{25}$, TWEAK ${ }^{30}$ ) in a convenience sample of up to ten adult stable heart transplant patients each. Patients were informed that nurses were piloting instruments and that their responses would not be recorded. Nurses could document their remarks on the content and use of the questionnaires on a standardized sheet provided by the researchers.

Afterwards, we conducted a qualitative study using a phenomenological approach, aiming to understand nurses' experiences when using these screening tools. A topic guide was developed prior to the interviews, addressing questions regarding the formulation of the items, ease of scoring, perceived length for completion, what they expect from a good screening instrument, and their knowledge about the current guidelines on alcohol use, the definition of at risk drinking and the definition of a standard drink. The interview concluded by asking them to provide a rank order from the most liked to the least preferred 
instrument. Interviews were audiotaped and anonymized, ensuring confidentiality of information given by participating nurses.

Interviews were transcribed verbatim, remarks indicated, and similar remarks across the interviews were subsequently grouped and presented in table format, as well as an indication of the frequency of a given comment.

Results were discussed afterwards during a focus group with an interdisciplinary group of transplant professionals who did not participate in the interview, during which it was decided which instrument would be selected to undergo cognitive debriefings with patients.

\section{RESULTS}

The characteristics of the four nurses participating in this step are summarized in table 2 . The three instruments were presented to 32 patients in total. Three participants did not know the definition of a standard drink and were not aware of the guidelines regarding acceptable alcohol use, indicating a need for further education.

\section{INSERT TABLE 2 ABOUT HERE}

\section{Summary of remarks on each of the three screening instruments}

AUDIT-C: All nurses evaluated the use and scoring of this instrument as easy. Yet, all participants noted that further screening could not be stopped, even if a patient indicated he or she is never drinking alcohol on the first item. They suggested offering the possibility to skip the remaining questions if the first item indicates no alcohol use. One nurse also indicated that it might be difficult to remember "how often did you have six or more drinks on one occasion".

Five-Shot: This instrument was also easy to complete, but required more time than the AUDIT-C. Question three (have people annoyed you by criticising your drinking) was also perceived as intrusive and stigmatizing by one nurse, and another nurse indicated that using the same cut-off for men and women was not correct, given the gender-specific guidelines for the definition of at risk drinking.

This article is protected by copyright. All rights reserved 
TWEAK: Although scoring was easy, more time was needed to complete this instrument compared to the other instruments. Yet, several comments on unclear phrasings or vague language were given, and two nurses indicated that it was not possible to indicate complete abstinence based on this instrument.

\section{Selection of preferred instrument}

Three out of the four participants selected the AUDIT-C as their most preferred instrument, as it is short, user-friendly and consists of clearly formulated questions (the fourth nurse had a slight preference for the five Shot over the AUDIT-C). Yet, it was suggested to add an introduction, explaining the purpose of this questionnaire, and to also explain what is meant by a standard alcohol unit. During the focus group, the following additional changes were suggested:

1) The response option "never" was added to question one (how often did you have a drink containing alcohol in the past year), followed by some probing questions: "Really never? Not even on certain occasions?" to maximize a trustful response.

2) The second question (How many standard drinks containing alcohol do you have on a typical day) was replaced by an alternative translation also available in the literature (how many drinks containing alcohol do you have on a typical day when you are drinking), as the latter might circumvent misconceptions regarding the definition of a standard drink.

\section{STEP 4: COGNITIVE DEBRIEFINGS WITH PATIENTS}

\section{METHODS}

In order to check the clarity of instructions and wording of the modified AUDIT-C, cognitive debriefing interviews were conducted in a convenience sample of heart transplant patients. Eligible patients had to be 18 years or older, have a scheduled visit at the outpatient clinic or were hospitalized for their annual check-up visit, and Dutch speaking, and willing to provide informed consent. A researcher contacted potentially eligible patients by phone 1-3 days before their outpatient clinic visit, explaining the purpose of the study in a standardized way, and exploring their interest to participate. If interested, a time and place for an in-person meeting at the clinic was scheduled. During this encounter, informed consent was asked, after which the researcher completed the instrument, inviting patients to think aloud. This methodology allows patients to verbalize any thoughts, feedback or feelings when being interviewed regarding their alcohol use. Comments after the instructions, or after each question were noted on a standardized sheet and summarized at the end of each interview. For all comments provided, the 
researchers evaluated whether changes to the AUDIT-C were needed. Selection of participants continued until no new comments on the clarity of wording or instructions emerged.

\section{RESULTS}

In total, 16 patients participated in the cognitive debriefings. Fifteen patients were male, with a median age of 67 years (range: 34 to 85 years), and a median time since transplantation of 13 years (range: from 3 months to 21 years). Six patients were hospitalized at the time of the interviews. All participants considered the introduction as clear, and the majority understood why screening for alcohol use is relevant. Similarly, the questions were considered concise and clear, and were not perceived as intrusive. It was only suggested to clarify what is meant by a "typical day". This suggestion was integrated in the final version of the AUDIT-C, before carrying out the final step of this project.

\section{STEP 5: IMPLEMENTATION OF THE INSTRUMENT IN CLINICAL PRACTICE}

\section{METHODS}

\section{Design, sample and setting}

This cross-sectional study aimed to implement the AUDIT-C in clinical practice in a convenience sample of heart transplant patients to check the prevalence of at risk drinking. As a secondary aim, we also explored whether at risk drinking was associated with gender, age, post-transplant status, employment status, or educational level. The following inclusion criteria were used: being 18 years or older, Dutch speaking, having a scheduled outpatient follow-up visit or a planned hospitalization at the heart transplant ward for annual in-patient check-up between February 24, 2017 and March 24, 2017, and capable and willing to provide written informed consent.

\section{Variables and measurement}

Demographic characteristics, as well as time since transplant were assessed by means of a self-report interview developed for the purpose of this study. Table 3 provides an overview of the clinical and demographic characteristics collected, as well as their response categories.

\section{INSERT TABLE 3 ABOUT HERE}

This article is protected by copyright. All rights reserved 
Patients were also asked to answer the 3 items of the modified version of the AUDIT-C during a brief interview, as described above. The total score on the 3 items ranges from 0 to 12 , with a score of 4 or higher for men and a score of 3 or more for women indicating at risk drinking.

\section{Procedure}

This study was approved by the ethical committee of the University Hospitals of Leuven. Two students of the Master of Nursing Science program of our university managed the data collection. The Advanced Practice Nurse of the heart transplant program checked all patients with a scheduled in- or outpatient clinic visit during the one-month data collection period for eligibility. The students first explained the purpose of the assessment in a standardized way in a separate room at the ward, and the interview was completed once informed consent was provided. Patients were informed that their responses would not be shared with the transplant team, and that the project was meant to find out whether using the AUDIT$\mathrm{C}$ in clinical practice is feasible and yield trustworthy results.

\section{Analyses}

The statistical software program SPSS (version 24; ibm.com) was used for data analysis. Descriptive statistics were used as appropriate, depending on the measurement level and distribution of the data. The proportion of patients with at risk drinking was expressed as a percentage. A Chi-square test was used to explore the association between at risk drinking and respectively gender and employment status. The Mann-Whitney $U$ test was used to explore differences in at risk drinking with respect to age, educational level, and time since transplant, respectively. Significance was set at $p<0.05$.

\section{RESULTS}

\section{Sample characteristics}

Within the study period, 176 patients had a scheduled clinic visit, of which 34 did not meet the inclusion criteria. Twelve patients refused to participate, resulting in a total sample of 130 heart transplant patients available for data analysis (91.6\% response rate). Table 3 contains an overview of the sample's demographic and clinical characteristics. The median age was 62 years, $69.2 \%$ were married or living together, $50 \%$ were retired, and $34.6 \%$ had a higher education. Median time since transplant was 9.5 years.

\section{Proportion of patients with at risk drinking}

This article is protected by copyright. All rights reserved 
105 of the 130 patients indicated using alcohol (80.8\%), of which 36 patients had at risk drinking (i.e. $27.6 \%$ of the total sample and $34.3 \%$ of those patients admitting drinking alcohol).

\section{Association between demographic characteristics and at risk drinking}

As shown in table 3, more men $(38.8 \%)$ than women $(20 \%)$ seem to have at risk drinking, yet this trend was not statistically significantly different. No other differences could be observed for any of the other demographic or clinical variables collected.

This article is protected by copyright. All rights reserved 


\section{DISCUSSION}

Given that small volumes of alcohol intake can already have adverse health outcomes ${ }^{1,32}$, regular screening in daily clinical practice is indicated. Although many screening instruments exist, it remained unclear which short, validated self-report screening instruments for at risk drinking were most suitable and user-friendly for use in routine post-transplant follow-up. By using a multi-method approach, including a literature search, expert, professionals and patient involvement, we were able to identify the AUDIT-C ${ }^{10-12}$ as the most suitable instrument.

Because of its inherent risk for underreporting, self-report instruments of course cannot replace more reliable alcohol use methods, such as a psychiatric diagnostic interview, or biomarkers, including e.g. gamma-glutamyltransferase (GGT), urinary ethyl glucuronide ( $\mathrm{UEtG}$ ), mean corpuscular volume (MCV) or Carbohydrate deficient transferrin (CDT) ${ }^{33-34}$. Yet, these methods are most often used in case of suspected alcohol dependence or abuse, and not to identify all patients with at risk drinking patterns. Moreover, in other chronically ill patient populations, the AUDIT-C showed a high sensitivity compared to diagnostic interviews ${ }^{10,12}$. Although further research is needed, it is therefore likely that the AUDIT-C has good validity in transplant populations also.

In fact, after implementing the AUDIT-C, we observed that roughly one out of three patients who drink alcohol, do so at a level endangering their health. This proportion is five times higher than the $6 \%$ reported in the report of the National Health Survey of Belgium ${ }^{35}$, yet the latter used different questions. The percentage observed within our heart transplant program is also twice as high as the $15 \%$ at risk drinking reported in a recently published meta-analysis in solid organ transplantation ${ }^{36}$. Yet, studies almost exclusively focused on liver transplant patients, a population known to include a significant portion of patients with a history of alcohol-related problems who are closely monitored to prevent alcohol use relapse post-transplant. Few studies looked at the prevalence of at risk drinking in other solid organ transplantation. In any case, the high prevalence observed in our heart transplant population flags a need for supportive interventions. The Brief intervention for Hazardous and harmful drinking, a manual for use in primary care, developed by the World Health Organization might present a good starting point in this regard ${ }^{37}$.

This study is characterized by a number of strengths, including its systematic, stepwise approach, combining a comprehensive literature search, expert, professional and patient involvement. Although we

This article is protected by copyright. All rights reserved 
evaluated 24 instruments in detail, it is however, possible, that other relevant self-report instruments might have been missed. Moreover, an unambiguous international definition of at risk drinking, as well as a standard alcohol unit, is currently lacking, making it difficult to compare existing instruments and to implement guidelines in transplant routine care. In line with the national guidelines available at the start of the project, we considered drinking more than 3 units daily for men and more than 2 units for women as at risk drinking. With newer evidence emerging, showing that the health risk becomes already apparent at lower levels of alcohol intake ${ }^{38}$, the threshold of acceptable alcohol use will most likely be lowered in the near future and will be the same for both sexes. Meanwhile, it is recommended that transplant centers have an agreed upon definition of acceptable alcohol use and a standard alcoholic drink in place to facilitate education, screening and, in case of at risk drinking, supportive interventions. Moreover, future research should focus on selecting an appropriate screening tools to detect harmful alcohol use already prior to transplantation, given that harmful alcohol use can be present in all solid organ transplant candidates and not only in liver transplant candidates, and that its presence often remains unnoticed without formal assessment. We will explore whether the AUDIT-C can be used successfully in transplant candidates also.

To summarize, our rigorous approach enabled us to select a screening instrument that both professionals and patients find acceptable to use within transplant follow-up care. In line with the principles of implementation science, stakeholder involvement is key to realize successful and sustainable changes in clinical practice.

\section{AUTHOR CONTRIBUTION}

Lieza Verhalle:

Kristof Van Bockstaele:

Nathalie Duerinckx:

Jasper Vanhoof:

Katrien Dierickx:
Concept/design of STEP 1 to 4 of the study, data collection, data analysis and interpretation, Drafting of the article

Concept/design of STEP 1 to 4 of the study, data collection, data analysis and interpretation, Critical review of the article

Concept/design of STEP 1 to 5 of the study, data analysis and interpretation, critical review of the article

Concept/design of STEP 1 to 5 of the study, data analysis and interpretation, critical review of the article

Concept/design of STEP 1 to 5 of the study, data analysis and interpretation, critical review of the article

This article is protected by copyright. All rights reserved 
Leen Neyens:

Johan Van Cleemput:

Sabine Gryp:

Dominica Kums:

Katleen De Bondt:

Veronique Schaevers:

Florian Demuynck:

Anne Dewispelaere:

Fabienne Dobbels:
Concept/design of STEP 1 to 5 of the study, data analysis and interpretation, critical review of the article

Data interpretation, facilitation of data collection, critical review of the article

Data interpretation, facilitation of data collection, critical review of the article

Data collection, data interpretation, critically review of article

Concept/design of STEP 1 to 5 of the study, data interpretation, critical review of the article

Concept/design of STEP 1 to 5 of the study, data interpretation, critical review of the article

Concept/design of STEP 5 of the study, data collection, data analysis and interpretation, Critical review of the article

Concept/design of STEP 5 of the study, data collection, data analysis and interpretation, critical review of the article

Concept/design of STEP 1-5 of the study, supervising data collection, analysis and coordinating interpretation, co-writing of the article

Transplantation Innovation Team (TRANSIT): all people listed participated in data collection, or participated in meetings focusing on data analysis or interpretation, and reviewed the article

This article is protected by copyright. All rights reserved 


\section{REFERENCES}

1. World Health Organization. Global status report on alcohol and health 2018. Geneva: World Health Organization; 2018. Licence: CC (https://apps.who.int/iris/bitstream/handle/10665/274603/9789241565639-eng.pdf?ua=1)

2. Hasin DS, O'Brien CP, Auriacombe M, Borges G, Bucholz K, Budney A, et al. DSM-5 criteria for substance use disorders: recommendations and rationale. Am J Psychiatry. 2013;170(8):834-51.

3. Kalinowski A, Humphreys K. Governmental standard drink definitions and low-risk alcohol consumption guidelines in 37 countries. Addiction 2016;111(7):1293-1298.

4. Niemelä O. Biomarker-based approaches for assessing alcohol use disorders. Int J environ Res Public Health 2016;13(2):166.

5. Food and Drug Administration. Guidance for industry: patient-reported outcome measures: use in medical product development to support labeling claims 2009. (https://www.fda.gov/regulatoryinformation/search-fda-guidance-documents/patient-reported-outcome-measures-use-medicalproduct-development-support-labeling-claims)

6. https://www.health.belgium.be/nl/gezondheid/zorg-voor-jezelf/alcohol-tabak/alcohol

7. Higgins JPT, Green S (editors). Cochrane Handbook for Systematic Reviews of Interventions Version 5.1.0 [updated March 2011]. The Cochrane Collaboration, 2011. Available from www.handbook.cochrane.org.

8. Moher D, Liberati A, Tetzlaff J, et al. Preferred reporting items for systematic reviews and metaanalysis: the PRISMA statement. PLoS Med 2009;6(7):e1000097.

9. Donovan DM, Kivlahan DR, Doyle SR, Longabaugh R, Greenfield SF. Concurrent validity of the Alcohol Use Disorders Identification Test (AUDIT) and AUDIT zones in defining levels of severity among out-patients with alcohol dependence in the COMBINE study. Addiction. 2006;101(12):1696-704.

10. Dawson DA, Grant BF, Stinson FS, Zhou Y. Effectiveness of the derived Alcohol Use Disorders Identification Test (AUDIT-C) in screening for alcohol use disorders and risk drinking in the US general population. Alcohol Clin Exp Res. 2005;29(5):844-54.

11. Kaarne T, Aalto M, Kuokkanen M, Seppa K. AUDIT-C, AUDIT-3 and AUDIT-QF in screening risky drinking among Finnish occupational health-care patients. Drug Alcohol Rev. 2010;29(5):563-7.

12. Bradley KA, Bush KR, Epler AJ, Dobie DJ, Davis TM, Sporleder JL, et al. Two brief alcohol-screening tests From the Alcohol Use Disorders Identification Test (AUDIT): validation in a female Veterans Affairs patient population. Arch Intern Med. 2003;163(7):821-9.

This article is protected by copyright. All rights reserved 
13. Johnson JA, Bembry W, Peterson J, Lee A, Seale JP. Validation of the ASSIST for Detecting Unhealthy Alcohol Use and Alcohol Use Disorders in Urgent Care Patients. Alcohol Clin Exp Res. 2015;39(6):1093-9.

14. Ali R, Meena S, Eastwood B, Richards I, Marsden J. Ultra-rapid screening for substance-use disorders: the Alcohol, Smoking and Substance Involvement Screening Test (ASSIST-Lite). Drug Alcohol Depend. 2013;132(1-2):352-61.

15. Bischof G, Reinhardt S, Grothues J, Meyer C, John U, Rumpf HJ. Development and evaluation of a screening instrument for alcohol-use disorders and at-risk drinking: the brief alcohol screening instrument for medical care (BASIC). J Stud Alcohol Drugs. 2007;68(4):607-14.

16. Rumpf HJ, Hapke U, Meyer C, John U. Screening for alcohol use disorders and at-risk drinking in the general population: psychometric performance of three questionnaires. Alcohol Alcohol. 2002;37(3):261-8.

17. Dawe SL, Natalie J Hides, Leanne Kavanagh, David J Mattick, Richard P. Review of diagnostic screening instruments for alcohol and other drug use and other psychiatric disorders - National Drug Strategy Monograph 48 - screening_assessment_review.pdf. 2002. Report No.: 064282124 0.

18. Rumpf HJ, Hapke U, Hill A, John U. Development of a screening questionnaire for the general hospital and general practices. Alcohol Clin Exp Res. 1997;21(5):894-8.

19. Kano MY, Santos MA, Pillon SC. [Use of alcohol in the elderly: transcultural validation of the Michigan Alcoholism Screening Test - Geriatric Version (MAST-G)]. Rev Esc Enferm USP. 2014;48(4):648-55.

20. Connor JP, Grier M, Feeney GF, Young RM. The validity of the Brief Michigan Alcohol Screening test (bMAST) as a problem drinking severity measure. J Stud Alcohol Drugs 2007;68(5): 771-779.

21. Hays RD, Revetto JP. Old and new MMPI-derived scales and the short-MAST as screening tools for alcohol disorder. Alcohol Alcohol 1992;27(6):685-695.

22. Malet L, Schwan R, Boussiron D, Aublet-Cuvelier B, Llorca PM. Validity of the CAGE questionnaire in hospital. Eur Psychiatry. 2005;20(7):484-9.

23. Dewost AV, Michaud P, Arfaoui S, Gache P, Lancrenon S. Fast alcohol consumption evaluation: a screening instrument adapted for French general practitioners. Alcohol Clin Exp Res. 2006;30(11):1889-95.

24. Hodgson R, Alwyn T, John B, et al. The FAST alcohol screening test. Alcohol Alcohol 2002;37(1):6166.

This article is protected by copyright. All rights reserved 
25. Meneses-Gaya C, Zuardi AW, Loureiro SR, Hallak JE, Trzesniak C, de Azevedo Marques JM, et al. Is the full version of the AUDIT really necessary? Study of the validity and internal construct of its abbreviated versions. Alcohol Clin Exp Res. 2010;34(8):1417-24.

26. Agabio R, Gessa GL, Montisci A, Finco G, Contu P, Bedogni G, et al. Use of the screening suggested by the National Institute on Alcohol Abuse and Alcoholism and of a newly derived tool for the detection of unhealthy alcohol drinkers among surgical patients. J Stud Alcohol Drugs. 2012;73(1):126-33.

27. Fulbrook $P$, Lawrence $P$, Watt K. Validity of the Paddington Alcohol Test in an Australian Emergency Departmentdagger. Alcohol Alcohol. 2015;50(4):407-12.

28. Cherpitel CJ, Ye Y. Performance of the RAPS4/RAPS4-QF for DSM-5 compared to DSM-IV alcohol use disorders in the general population: Data from the 2000-2010 National Alcohol Surveys. Drug Alcohol Depend. 2015;151:258-61.

29. Sokol RJ, Martier SS, Ager JW. The T-ACE questions: practical prenatal detection of risk-drinking. Am J obset Gynecol 1989;160(4):863-870.

30. Chan AW, Pristach EA, Welte JW, Russell M. Use of the TWEAK test in screening for alcoholism/heavy drinking in three populations. Alcohol Clin Exp Res 1993;17(6):1188-1192.

31. Wild D, Grove A, Martin M, et al. Principles of good practice for the translation and cultural adaptation process for patient-reported outcomes (PRO) measures: report of the ISPOR task force for translation and cultural adaptation. Value Health 2005;8(2):94-104.

32. Rehm J, Gmel GE Sr, Gmel G, et al. The relationship between different dimensions of alcohol use and the burden of disease - an update. Addiction 2017;112(6):968-1001.

33. Liangpunsakul S, Lai X, Ross RA, et al. Novel serum biomarkers for detection of excessive alcohol use. Alcohol Clin Res 2015;39(3):556-565.

34. Ustün , Compton W, Mager D, et al. WHO study on the reliability and validity of the alcohol and drug use disorder instruments: overview of methods and results. Drug Alcohol Depend 1997;47(3):161-169.

35. Gisle L, Demarest S, Drieskens S. Belgian Health survey 2018: the use of alcohol. Brussels, Belgium. Sciensano: report number D/2019/14.440/56. Available at: https://his.wivisp.be/nl/Gedeelde\%20\%20documenten/AL_NL_2018.pdf

36. Dobbels F, Denhaerynck K, Klem ML, et al. Correlates and outcomes of alcohol use after single solid organ transplantation: A systematic review and meta-analysis. Transplant Rev (Orlando) 2019;33(1):17-28.

This article is protected by copyright. All rights reserved 
37. Babor TF, Higgins-Biddle JC (editors). Brief intervention for Hazardous and Harmful Drinking: A manual for use in primary Care. World Health Organization: Department of Mental Health and Substance $\quad 2001 . \quad$ Dependence Available at: https://www.who.int/substance_abuse/publications/audit_sbi/en/\#: :text=It\%20provides\%20a\% 20framework\%20for,specific\%20consequences\%20of\%20harmful\%20drinking.

38. Roerecke M, Rehm J. Alcohol intake revisited: risks and benefits. Curr Atheroscler Rep 2012; 14:556-562. 


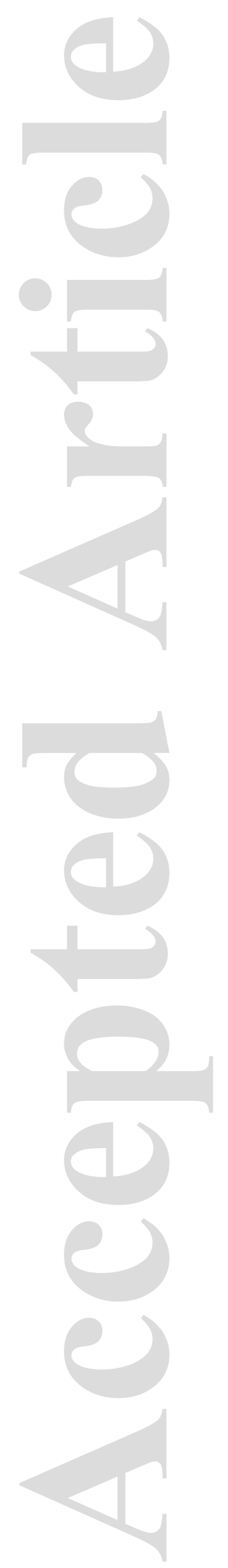

This article is protected by copyright. All rights reserved 
TABLE 1 - overview of the instruments identified during the literature search (step 1) and their overall evaluation of potential suitability (step 2):

\begin{tabular}{|c|c|c|c|c|c|c|c|c|}
\hline & $\begin{array}{l}\text { Screening } \\
\text { of at risk } \\
\text { drinking }\end{array}$ & $\begin{array}{l}\text { Number } \\
\text { of } \\
\text { questions }\end{array}$ & Manual available & $\begin{array}{l}\text { Diagnostic } \\
\text { interview* }\end{array}$ & Settings in which the instrument was tested & $\begin{array}{l}\text { Free use in } \\
\text { clinical setting }\end{array}$ & Total score & \\
\hline $\begin{array}{l}\text { Screening } \\
\text { test }\end{array}$ & $\begin{array}{l}\text { Yes: } 1 \\
\text { No: } 0\end{array}$ & $\begin{array}{l}\leq 5: 1 \\
>5: 0\end{array}$ & $\begin{array}{l}\text { Available: } 1 \\
\text { Not available: } 0\end{array}$ & & $\begin{array}{l}\text { Hospital setting: } 1 \\
\text { Not in hospital setting: } 0\end{array}$ & $\begin{array}{l}\text { Free use: } 1 \\
\text { No free use: } 0\end{array}$ & $\begin{array}{l}\text { Number of } \\
\text { times ' } 1 \text { ', }\end{array}$ & Acronym screening test \\
\hline AUDIT & 1 & $\mathbf{0}$ & 1 & $1(1)$ & $\begin{array}{l}\mathbf{1} \\
\text { several medical settings }\end{array}$ & 1 & $5 / 6$ & $\begin{array}{l}\text { Alcohol Use Disorders } \\
\text { Identification Test }\end{array}$ \\
\hline AUDIT-C & 1 & 1 & 1 & $1(2)$ & $\begin{array}{l}\mathbf{1} \\
\text { several medical settings }\end{array}$ & 1 & $6 / 6$ & $\begin{array}{l}\text { Alcohol Use Disorders } \\
\text { Identification Test - } \\
\text { Consumption }{ }^{10-12}\end{array}$ \\
\hline AUDIT-QF & 1 & 1 & No information & $\mathbf{0}(3)$ & $\begin{array}{l}\mathbf{0} \\
\text { several emergency services }\end{array}$ & No information & $2 / 6$ & $\begin{array}{l}\text { Alcohol Use Disorders } \\
\text { Identification Test - Quantity } \\
\text { Frequency }\end{array}$ \\
\hline $\begin{array}{l}\text { AUDIT-3 } \\
\text { or } \\
\text { M-SASQ }\end{array}$ & 1 & 1 & 1 & $1(4)$ & $\begin{array}{l}\text { 0 } \\
\text { occupational medicine service }\end{array}$ & No information & $4 / 6$ & $\begin{array}{l}\text { Modified Single Alcohol } \\
\text { Screenings Question }\end{array}$ \\
\hline ASSIST & $\mathbf{0}$ & $\mathbf{0}$ & 1 & $1(5)$ & $\begin{array}{l}\mathbf{0} \\
\text { first-line care and emergency services }\end{array}$ & 1 & $3 / 6$ & $\begin{array}{l}\text { Alcohol, Smoking and } \\
\text { Substance Involvement } \\
\text { Screening Test }{ }^{13}\end{array}$ \\
\hline $\begin{array}{l}\text { ASSIST } \\
\text { LITE }\end{array}$ & $\mathbf{0}$ & $\mathbf{0}$ & No information & $1(6)$ & $\begin{array}{l}\text { 0 } \\
\text { general medical settings in first-line care }\end{array}$ & No information & $1 / 6$ & $\begin{array}{l}\text { Alcohol, Smoking and } \\
\text { Substance Involvement } \\
\text { Screening Test }{ }^{14}\end{array}$ \\
\hline BASIC & 1 & $\mathbf{0}$ & No information & $1(7)$ & 1 & No information & $3 / 6$ & (No information on acronym) \\
\hline
\end{tabular}

This article is protected by copyright. All rights reserved 


\begin{tabular}{|c|c|c|c|c|c|c|c|c|}
\hline & & & & & $\begin{array}{l}\text { general hospitals and general practioner } \\
\text { offices }\end{array}$ & & & 15 \\
\hline LAST & $\mathbf{0}$ & $\mathbf{0}$ & No information & $1(8)$ & $\begin{array}{l}\mathbf{1} \\
\text { general hospitals and general practioner } \\
\text { offices }\end{array}$ & No information & $2 / 6$ & $\begin{array}{l}\text { Lübeck Alcohol Dependence } \\
\text { and Abuse Screening Test }{ }^{16}\end{array}$ \\
\hline MAST & $\mathbf{0}$ & $\mathbf{0}$ & 1 & $\mathbf{0}(9)$ & $\begin{array}{l}\mathbf{1} \\
\text { first-line care, general and clinical populations }\end{array}$ & $\mathbf{1}$ & $3 / 6$ & $\begin{array}{l}\text { Michigan Alcoholism } \\
\text { Screening Test }{ }^{17,18}\end{array}$ \\
\hline MAST-G & $\mathbf{0}$ & $\mathbf{0}$ & No information & $\mathbf{1}(10)$ & $\begin{array}{l}\text { O } \\
\text { health centra, outpatient clinic general hospital }\end{array}$ & No information & $1 / 6$ & $\begin{array}{l}\text { Michigan Alcoholism } \\
\text { Screening Test - } \\
\text { Geriatric Version }^{19}\end{array}$ \\
\hline BMAST & $\mathbf{0}$ & $\mathbf{0}$ & No information & $1(9)$ & $\begin{array}{l}\mathbf{1} \\
\text { general hospital, emergency service }\end{array}$ & No information & $2 / 6$ & $\begin{array}{l}\text { Brief Michigan Alcoholism } \\
\text { Screening Test }{ }^{20}\end{array}$ \\
\hline SMAST-13 & $\mathbf{0}$ & $\mathbf{0}$ & 1 & $1(11)$ & $\begin{array}{l}\text { 1 } \\
\text { general practioner offices and general } \\
\text { hospitals }\end{array}$ & No information & $3 / 6$ & $\begin{array}{l}\text { Short Michigan Alcoholism } \\
\text { Screening Test }{ }^{21}\end{array}$ \\
\hline CAGE & $\mathbf{0}$ & 1 & 1 & $1(12)$ & $\begin{array}{l}\mathbf{1} \\
\text { university, ambulant settings and hospitals }\end{array}$ & $\mathbf{1}$ & $5 / 6$ & $\begin{array}{l}\text { Cutdown, Annoyed, Guilty, } \\
\text { Eye-opener }{ }^{22}\end{array}$ \\
\hline FACE & 1 & 1 & No information & $1(13)$ & $\begin{array}{l}\mathbf{0} \\
\text { general practioner offices }\end{array}$ & 1 & $4 / 6$ & $\begin{array}{l}\text { Fast Alcohol Consumption } \\
\text { Evaluation }{ }^{23}\end{array}$ \\
\hline FAST & 1 & 1 & 1 & $1(14)$ & $\begin{array}{l}\mathbf{0} \\
\text { several medical settings }\end{array}$ & $\mathbf{1}$ & $5 / 6$ & $\begin{array}{l}\text { Fast Alcohol Screening Test } \\
24-25\end{array}$ \\
\hline $\begin{array}{l}\text { FIVE- } \\
\text { SHOT }\end{array}$ & 1 & 1 & 1 & $\mathbf{1}(14)$ & $\begin{array}{l}\mathbf{1} \\
\text { several medical settings }\end{array}$ & 1 & $6 / 6$ & $\begin{array}{l}\text { (No information on acronym) } \\
25\end{array}$ \\
\hline NIAAA-2Q & 1 & 1 & No information & $\mathbf{0}(15)$ & 1 & No information & $3 / 6$ & National Institute on Alcohol \\
\hline
\end{tabular}

This article is protected by copyright. All rights reserved 


\begin{tabular}{|c|c|c|c|c|c|c|c|c|}
\hline NIAAA-4Q & & & & & university hospital & & & $\begin{array}{l}\text { Abuse and Alcoholism - } \\
2 / 4 \text { Questions }{ }^{26}\end{array}$ \\
\hline PAT & 1 & 1 & 1 & $\mathbf{0}(16)$ & $\begin{array}{l}\mathbf{0} \\
\text { emergency services }\end{array}$ & No information & $3 / 6$ & Paddington Alcohol Test ${ }^{27}$ \\
\hline RAPS4 & $\mathbf{0}$ & 1 & No information & $\mathbf{1}(17)$ & $\begin{array}{l}\mathbf{0} \\
\text { emergency services }\end{array}$ & 1 & $3 / 6$ & $\begin{array}{l}\text { Rapid Alcohol Problems } \\
\text { Screen } 4{ }^{28}\end{array}$ \\
\hline RAPS4-QF & 1 & $\mathbf{0}$ & No information & $\mathbf{1}(17)$ & $\begin{array}{l}\text { 1 } \\
\text { emergency service, ambulant and clinical } \\
\text { settings }\end{array}$ & No information & $3 / 6$ & $\begin{array}{l}\text { Rapid Alcohol Problems } \\
\text { Screen } 4 \text { - } \\
\text { Quantity Frequency }{ }^{28}\end{array}$ \\
\hline T-ACE & 1 & 1 & No information & $\mathbf{0}(18)$ & $\begin{array}{l}1 \\
\text { outpatient clinic hospital and surrounding } \\
\text { community }\end{array}$ & 1 & $4 / 6$ & $\begin{array}{l}\text { Tolerance, Annoyed, } \\
\text { Cut-down, Eye-opener }{ }^{29}\end{array}$ \\
\hline TWEAK & 1 & 1 & 1 & $1(19)$ & $\begin{array}{l}\mathbf{1} \\
\text { emergency services, first-line care and clinical } \\
\text { setting }\end{array}$ & 1 & $6 / 6$ & $\begin{array}{l}\text { Tolerance, Worried, Eye } \\
\text { Opener, Amnesia, K/Cut- } \\
\text { down }^{30}\end{array}$ \\
\hline
\end{tabular}

* Diagnostic interview: We checked whether the questionnaire has satisfactory psychometric properties, using a formal psycho-diagnostic interview as the gold standard. A sensitivity and specificity of $70 \%$ or higher was considered satisfactory. Sensitivity refers to the ability of a given questionnaire to identify those with at-risk drinking correctly (i.e. those that were identified by the diagnostic interview as having at risk drinking) (true positive rate). Specificity is the ability of the questionnaire to identify those without at-risk drinking correctly (as determined by the diagnostic interview) (true negative rate).

This article is protected by copyright. All rights reserved 


\section{TABLE 2 - demographic characteristics nurses:}

\begin{tabular}{|c|c|c|}
\hline \multicolumn{2}{|c|}{ Demografic characteristics nurses } & Total $(n=4)$ \\
\hline \multicolumn{3}{|c|}{ Gender } \\
\hline & Man & 0 \\
\hline & Woman & 4 \\
\hline \multicolumn{3}{|c|}{ Age (in years) } \\
\hline & $<40$ years & 2 \\
\hline & 41 years or older & 2 \\
\hline \multicolumn{3}{|c|}{ Education level } \\
\hline & licensed practical/graduate nurse & 1 \\
\hline & registered nurse/bachelor & 1 \\
\hline & master & 1 \\
\hline & phd & 1 \\
\hline \multicolumn{3}{|c|}{ Ward } \\
\hline & Cardiology/Heart Transplantation Ward & 2 \\
\hline & Cardiology/Heart Transplantation Day Unit & 2 \\
\hline \multicolumn{3}{|c|}{ Work experience (in years) } \\
\hline & $<10$ years & 2 \\
\hline & 10 years or more & 2 \\
\hline \multicolumn{3}{|c|}{ Experience with screening for alcohol use } \\
\hline & no & 0 \\
\hline & limited & 1 \\
\hline & yes & 3 \\
\hline \multicolumn{3}{|c|}{$\begin{array}{l}\text { How frequently do you expect alcohol problems being } \\
\text { present in transplant patients? }\end{array}$} \\
\hline & not present & 0 \\
\hline$\sqrt{3}$ & rare & 3 \\
\hline 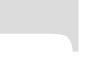 & frequently present & 1 \\
\hline
\end{tabular}

This article is protected by copyright. All rights reserved 
TABLE 3 - demographic and clinical characteristics patients:

\begin{tabular}{|c|c|}
\hline Demographic and clinical characteristics patients & Total $(n=130 ; 100 \%)$ \\
\hline \multicolumn{2}{|l|}{ Gender } \\
\hline Man & $96(73,8 \%)$ \\
\hline Woman & $34(26,2 \%)$ \\
\hline \multicolumn{2}{|l|}{ Age (in years) } \\
\hline Median & 62 \\
\hline Interquartile range & 21,25 \\
\hline Minimum & 21 \\
\hline Maximum & 80 \\
\hline \multicolumn{2}{|l|}{ Education level (n,\%) } \\
\hline Lower education (high school not completed) & $13(10 \%)$ \\
\hline $\begin{array}{l}\text { Moderate education (high school completed or } \\
\text { vocational degree) }\end{array}$ & $72(55,4 \%)$ \\
\hline High education (bachelor degree or higher) & $45(34,6 \%)$ \\
\hline \multicolumn{2}{|l|}{ Marital status (n,\%) } \\
\hline Married/legally cohabiting & $90(69,2 \%)$ \\
\hline Unmarried/single & $22(16.9 \%)$ \\
\hline Divorced & $12(9,2 \%)$ \\
\hline Widower/widow & $6(4,6 \%)$ \\
\hline \multicolumn{2}{|l|}{ Living alone $(\mathrm{n}, \%)$} \\
\hline No & $106(81,5 \%)$ \\
\hline Yes & $24(18,5 \%)$ \\
\hline \multicolumn{2}{|l|}{ Cohabiting $(\mathrm{n}, \%)$} \\
\hline With partner & $95(73,1 \%)$ \\
\hline With someone else than partner & $11(8,5 \%)$ \\
\hline \multicolumn{2}{|l|}{ Employment (n, \%) } \\
\hline Employed & $25(19,2 \%)$ \\
\hline Retired & $65(50 \%)$ \\
\hline Disability income & $32(24.6 \%)$ \\
\hline Houseman/-wife / student / volunteer work & $5(3,8 \%)$ \\
\hline Unemployed / looking for a job & $3(1,5 \%)$ \\
\hline \multicolumn{2}{|l|}{ Number of years transplanted } \\
\hline Median & 9,5 \\
\hline Interquartile range & 13 \\
\hline Minimum & 1 \\
\hline Maximum & 26 \\
\hline Number of heart transplants $(\mathrm{n}, \%)$ & \\
\hline First & $127(97,7 \%)$ \\
\hline
\end{tabular}

This article is protected by copyright. All rights reserved 
This article is protected by copyright. All rights reserved 